Artigo

\title{
A "experiência" e o "esperançar" na Educação Matemática durante a pandemia de COVID-19
}

\author{
The "experience" and "the hope" in Mathematics Education \\ during the COVID-19 pandemic \\ La "experiencia" y la "esperanza" en la Educación Matemática \\ durante la pandemia de COVID-19
}

\author{
Luciane Mulazani dos Santos ${ }^{1}$ \\ [0000-0001-7617-7310] \\ Maria Caroline Silveira ${ }^{2}$ \\ [0000-0002-2656-6083] \\ Maura Pauletto Taschetto 3 \\ [0000-0002-6560-8928]
}

\begin{abstract}
Resumo
Para preservação da vida, as medidas de contenção da pandemia de COVID-19 transformaram nossas relações com o outro e com o ambiente que nos cerca, o que afetou a área da Educação das mais diferentes formas. As experiências em instituições educacionais passaram do presencial ao virtual, o que modificou as relações entre professores e alunos e, destes, com o conteúdo curricular e com os espaços onde se ensina e se aprende. Por um lado, professores se dedicaram a adaptar suas práticas para atuaram nesses novos ambientes; por outro, alunos e famílias se reorganizaram para fazer das casas o novo local de aprendizagem. Nesse contexto, às tecnologias digitais foi dada uma função quase que indispensável, pois é por meio delas que a não presença física consegue deslizar para a presença virtual, necessária para acontecimento das aulas remotas. Aos excluídos do acesso à internet e a equipamentos, uma grande parte dos estudantes brasileiros, infelizmente restam as adaptações que se fazem viáveis, como por exemplo, a aprendizagem por meio de materiais impressos preparados pelos professores. Durante parte da pandemia, as aulas presenciais foram completamente suspensas em todas as instituições educacionais; na data em que este artigo foi publicado, grande parte das escolas brasileiras já tinham voltado às aulas presenciais e o novo desafio que se apresenta é a retomada para superar da crise. A Educação Matemática, interessada em questões de pesquisa e em processos de ensino e aprendizagem, se preocupa em debater a crise educacional ligada à COVID-19, para refletir e agir na realidade que se apresenta e futura.
\end{abstract}

Palavras-chave: Educação Matemática. Formação de professores. Ensino e aprendizagem. Ensino remoto. Pandemia de COVID-19.

\footnotetext{
${ }^{1}$ luciane.mulazani@udesc.br, Doutora em Educação, Professora, Universidade do Estado de Santa Catarina (UDESC), Florianópolis/SC/Brasil.

2 profmariacaroline@gmail.com, Mestra em Ensino de Ciências, Matemática e Tecnologias, doutoranda em Educação, Professora, Rede Estadual de Educação de Santa Catarina, Joinville/SC/Brasil.

${ }^{3}$ maurataschetto@gmail.com, Mestra em Engenharia Mecânica, doutoranda em Educação, Professora, Rede Municipal de Educação de Florianópolis, Florianópolis/SC/Brasil.
} 


\begin{abstract}
In order to preserve life, the measures to contain the COVID-19 pandemic have transformed our relationships with others and with the environment around us, which has affected the area of Education in different ways. The experiences in educational institutions have gone from face-to-face to virtual, which has changed the relationships between teachers and students and, of these, with the curricular content and with the spaces where one teaches and learns. On the one hand, teachers dedicated themselves to adapting their practices to work in these new environments; on the other, students and families reorganized to make homes the new place of learning. In this context, digital technologies were given an almost indispensable function, because it is through them that the nonphysical presence can slide into the virtual presence, necessary for the event of remote classes. For those excluded from internet access and equipment, a large part of Brazilian students, unfortunately remain the adaptations that are viable, such as learning through printed materials prepared by teachers. During part of the pandemic, face-to-face classes were completely suspended in all educational institutions; on the date this article was published, most Brazilian schools had already returned to face-to-face classes and the new challenge is the resumption for overcome the crisis. Mathematics Education, interested in research issues and teaching and learning processes, is concerned with debating the educational crisis linked to COVID-19, to reflect and act in the present and future reality.
\end{abstract}

Keywords: Mathematics Education. Teacher training. Teaching and learning. Remote teaching. COVID19 pandemic.

\title{
Resumen
}

Con el fin de preservar la vida, las medidas para contener la pandemia de COVID-19 han transformado nuestras relaciones con los demás y con el entorno que nos rodea, lo que ha afectado al área de la Educación de diferentes maneras. Las experiencias en las instituciones educativas han pasado de presenciales a virtuales, lo que ha cambiado las relaciones entre docentes y alumnos y, de estas, con los contenidos curriculares y con los espacios donde se enseña y se aprende. Por un lado, los docentes se dedicaron a adaptar sus prácticas para trabajar en estos nuevos entornos; por otro, los estudiantes y las familias se reorganizaron para hacer de los hogares el nuevo lugar de aprendizaje. En este contexto, a las tecnologías digitales se les dio una función casi indispensable, porque es a través de ellas que la presencia no física puede deslizarse hacia la presencia virtual, necesaria para el evento de clases remotas. Para aquellos excluidos del acceso y equipo de internet, una gran parte de los estudiantes brasileños, desafortunadamente siguen siendo las adaptaciones que son viables, como el aprendizaje a través de materiales impresos preparados por los maestros. Durante parte de la pandemia, las clases presenciales fueron completamente suspendidas en todas las instituciones educativas; a la fecha en que se publicó este artículo, la mayoría de las escuelas brasileñas ya habían regresado a las clases presenciales y el nuevo desafío es la reanudación para superar la crisis. La Educación Matemática, interesada en temas de investigación y procesos de enseñanza y aprendizaje, se preocupa por debatir la crisis educativa vinculada al COVID-19, para reflexionar y actuar en la realidad presente y futura.

Palabras claves: Educación Matemática. Formación de profesores. Enseñando y aprendiendo. Enseñanza remota. Pandemia de COVID-19. 
A pandemia de COVID-194 impôs desafios às experiências humanas. Aprendemos com Jorge Larrosa que experiência "é o que nos passa, o que nos acontece, o que nos toca" (LARROSA, 2002, p. 21), única para cada pessoa porque, mesmo que se relacione a um mesmo acontecimento, ela (a experiência) tem a pessoa como local (LARROSA, 2011).

Quando compartilhamos das mesmas ideias de Larrosa sobre a experiência, como podemos olhar, compreender e lidar com as dores, incertezas e esperanças que pairam sobre o campo da educação enquanto vivemos as difíceis situações nas quais a doença nos colocou? Como a Educação Matemática se coloca nesse contexto perante o seu campo?

Figura 1 - Obra de @c.g.y.45

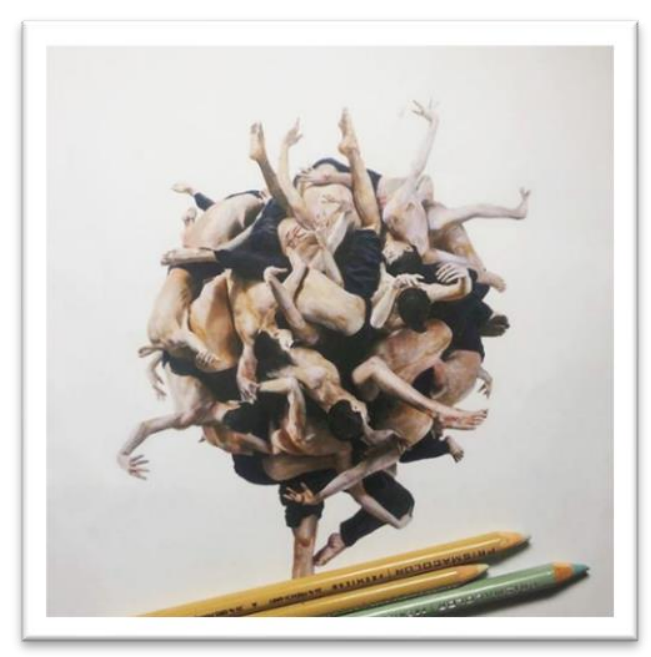

Fonte: CAM The Covid Art Museum ${ }^{5}$ - https://www.instagram.com/p/B99bCarHbcK

Conhecer diferentes respostas para essas (e mais) questões, construídas por diferentes pessoas vindas de vários lugares, pode fazer da experiência do outro ${ }^{6}$ algo que nos mostre que nossas angústias e expectativas, ainda que únicas, guardam semelhança com outras, o que pode nos ajudar, confortar e fortalecer. Em meio ao caos pandêmico, é isso que esta edição provoca, em torno da Educação Matemática.

Ainda que 2021 seja um ano triste em pandemia, tem o marco comemorativo do centenário de Paulo Freire 7 . Muito aprendemos com sua trajetória, ideias e escritos. Paulo Freire nos faz compreender que uma educação dialógica e libertadora é fundamental para que a sociedade se constitua para cidadania democrática, crítica e inclusiva, com respeito à diversidade da individualidade. (FREIRE, 1967, 1987, 1996, 1997, 2001). Essa compreensão é necessária para enxergarmos como a Educação brasileira do final do ano de 2019 estava em crise, sob efeito de diferentes problemas, muitos deles decorrentes de desmontes em políticas públicas, orçamentos, planos e fóruns democráticos institucionais, o que acentuou desigualdades, limitou oportunidades e abriu caminho para a proliferação de ataques, discursos e projetos equivocados e perversos, interessados em objetivos alheios à educação democrática, crítica e livre de preconceitos. E essa crise foi agravada a partir de 2020, quando em 11 de março a Organização Mundial da Saúde (OMS) declarou a pandemia de COVID-19.

\footnotetext{
${ }^{4}$ COVID-19 é uma doença infecciosa causada pelo novo coronavírus (SARS-CoV-2).

${ }^{5}$ Obras de arte da galeria virtual do CAM - The Covid Art Museum ilustram este artigo. A arte salva.

${ }^{6}$ Declaramos aqui nosso propósito de incluir todas as pessoas no discurso. Foi apenas por uma questão de organização da escrita que não adotamos, neste artigo, o tipo de notação "o/a".

${ }^{7}$ Paulo Reglus Neves Freire nasceu em 19 de setembro de 1921, em Recife, Pernambuco.
} 
Figura 2-Obra de @richardlemanz

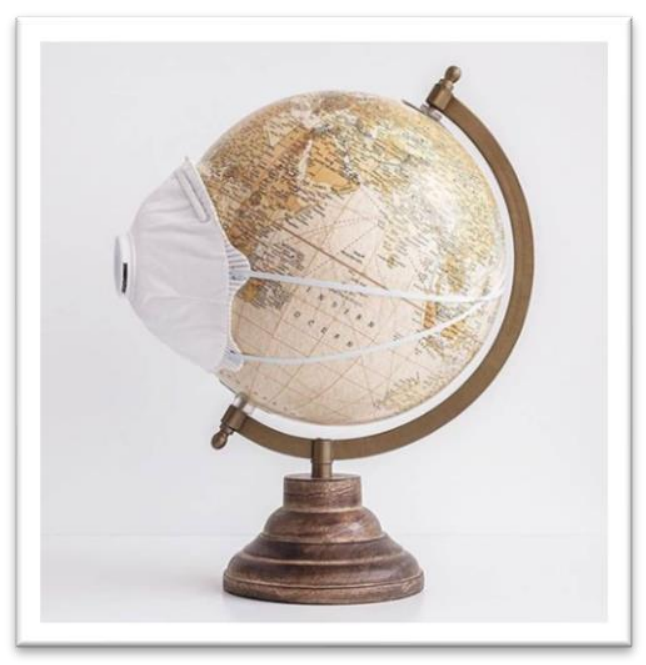

Fonte: CAM The Covid Art Museum - https://www.instagram.com/p/CErPRxNDc2I

A doença com caráter pandêmico levou os países a adotarem medidas para tentarem conter a propagação do vírus, a infecção e a morte de pessoas: restrições da movimentação humana em seus territórios, fechamento de fronteiras e de espaços públicos e privados para conter as pessoas em casa. Toda essa situação, inevitavelmente, provocou mudanças nas experiências das pessoas, seja no trabalho, no estudo ou no lazer, deixando o mundo diferente.

Figura 3-Obra de @icyandsot

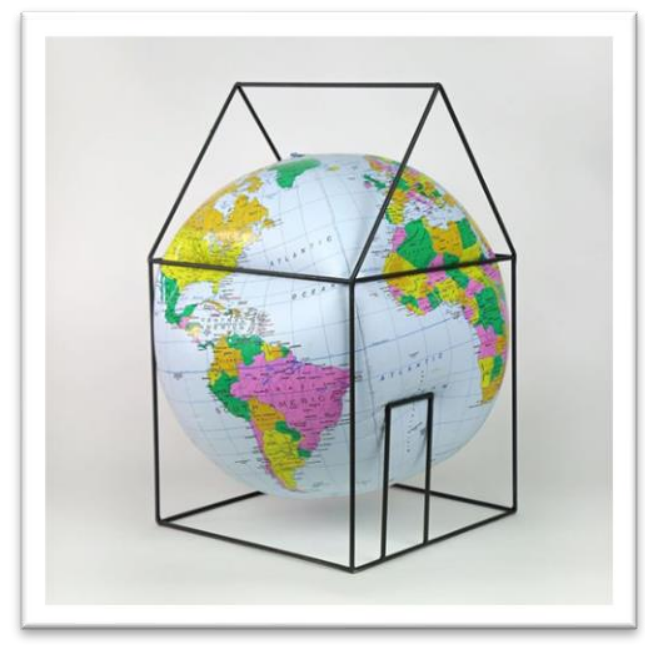

Fonte: CAM The Covid Art Museum - https://www.instagram.com/p/B HXwl7jCwV

No Brasil, a partir da segunda quinzena de março de 2020, cada Estado e Município, dentro daquilo que lhes compete na hierarquia do poder público, decretou medidas restritivas como o fechamento das instituições educacionais de todos os níveis e modalidades de ensino e a suspensão das aulas presenciais. Como solução para continuidade das atividades educacionais e para manutenção das relações entre alunos e professores, as instituições replanejaram partes de seus projetos pedagógicos para adotarem um modelo emergencial de aulas, realizadas de modo remoto. E, para dar conta desse modelo, entrou em cena, com 
força, a estrutura tecnológica que possibilita a comunicação e a interação professor/aluno/conteúdo de modo on-line, a distância, síncrono ou assíncrono.

Desde então, a rotina escolar passou a lidar com internet, wifi, smartphones, computadores, câmeras, microfones, aplicativos, plataformas, videoaulas, videochamadas, comunicação instantânea... de uma maneira não antes experimentada, mesmo nas realidades mais aderentes às tecnologias digitais. Para os casos - não poucos - de falta de acesso a esse tipo de tecnologia por parte dos alunos e dos professores, as aulas remotas utilizaram outras estratégias, como por exemplo o uso de materiais impressos. Esse é um problema que precisa de debate, principalmente no nosso país, que apresenta diversidade e desigualdade de condições em seu território.

Assim, durante grande parte da pandemia de COVID-19, as aulas foram ministradas sem contato físico presencial, em um modelo que recebeu diferentes denominações conforme a instituição onde foi adotado, como por exemplo ensino remoto, aulas virtuais, aulas remotas, ensino a distância etc. De toda forma, para realizá-las, professores ressignificaram suas práticas pedagógicas e, para participarem, alunos e famílias reorganizaram suas rotinas para receberem essas aulas em suas casas.

Se a educação brasileira já vivia uma crise, ela se acentuou durante a pandemia, pois foram escancarados problemas de desigualdade social que revelaram que, enquanto uma parte dos estudantes consegue participar de aulas remotas porque têm condições de utilizar internet e equipamentos, outra parte só consegue estudar porque recebe materiais impressos da escola ou diretamente de seus professores. Mais do que uma discussão sobre que tipo de recurso é utilizado para as aulas, importa refletirmos sobre como a falta dos recursos digitais impossibilita um mínimo de contato e interação entre professores e alunos para preservar pelo menos um pouco da dinâmica escolar que foi quebrada pelo isolamento social. As aulas síncronas, por exemplo, são importantes para permanência do vínculo entre professores e alunos e de alunos entre si.

Como, por muito tempo, as características e o tratamento da COVID-19 foram desconhecidos para a comunidade médica, tornou-se imprevisível uma solução rápida da situação, ainda que muitas pessoas imaginassem que a pandemia poderia ser revertida em poucos meses, pois se tratava de uma "gripezinha" que só causava morte de pessoas fracas e idosas.

Figura 4 - Situação epidemiológica da COVID-19 no mundo e no Brasil.

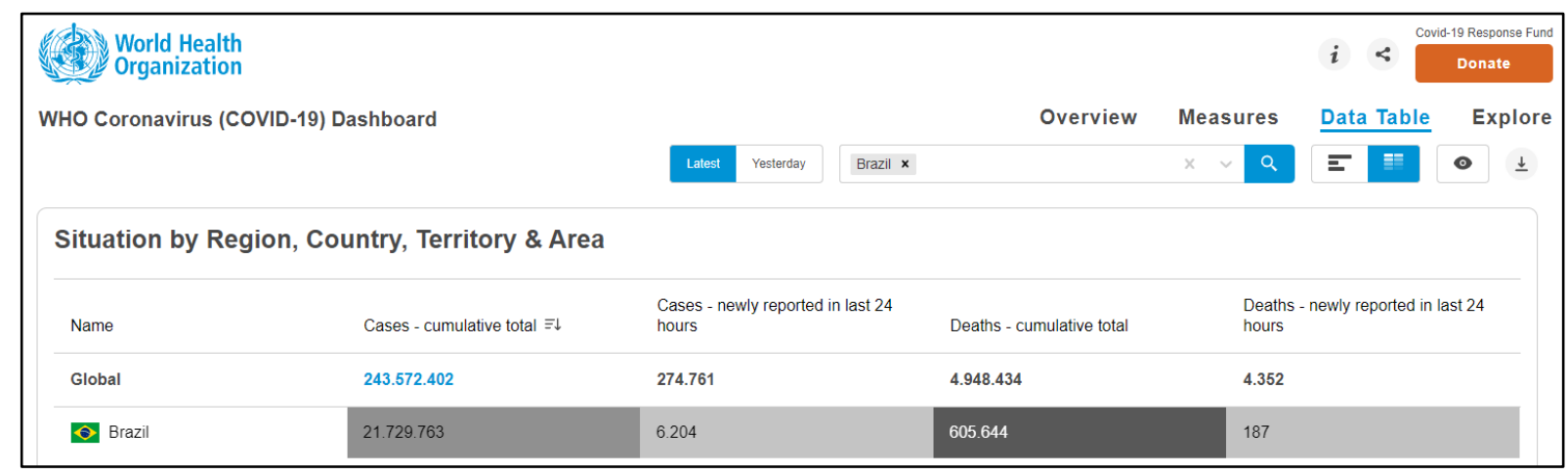

Fonte: WHO Coronavirus (COVID-19) Dashboard - https://covid19.who.int/table - dados de 26/10/2021.

Segundo dados da World Health Organization (WHO), mostrados na Figura 4, em 26/10/2021 (quando esse artigo foi finalizado), havia no mundo 243.572 .402 casos 
confirmados de COVID-19, incluídas 4.948.434 mortes. No Brasil, até a mesma data, havia 21.729.763 casos com 605.644 mortes. E a doença segue a nível mundial, com casos e mortes diários, como também pode ser visto na Figura 4.

Infelizmente, ainda não estamos completamente a salvo. Os números diários refletem situação preocupante, mas felizmente é menos grave do que aquela dos primeiros meses da pandemia, pois as medidas restritivas e preventivas vêm funcionando, bem como a ciência avançou no desenvolvimento de vacinas, mesmo tendo encontrado inacreditáveis discursos negacionistas e mentirosos em relação à imunização. A vacinação no Brasil iniciou em $17 / 01 / 2021$. Neste outubro de $2021,51,66 \%$ da população está completamente vacinada (com duas doses ou com dose única, de acordo com a vacina utilizada), o que corresponde a cerca de 110 milhões de brasileiros.

No jogo entre avanço da doença e imunização, estamos em processo de recuperação, numa combinação de permanência de algumas medidas restritivas e de flexibilização de outras. Nas instituições educacionais que já retomaram as aulas presenciais, protocolos obrigatórios de segurança sanitária tentam prevenir a contaminação pelo vírus enquanto imprimem novos códigos de normalidade às experiências e relações humanas que acontecem nesses espaços.

Figura 5 - Obra de @vitu_od

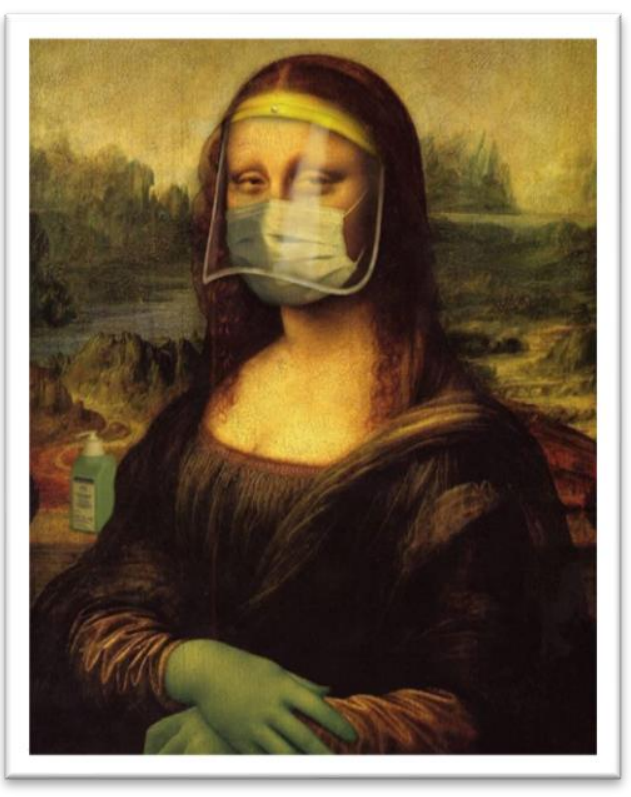

Fonte: CAM The Covid Art Museum - https://www.instagram.com/p/CCMXUVMi m2

Com a força e a pertinência do uso de gerundismo neste caso, podemos afirmar que a Educação Matemática está sendo repensada. Educação a Distância? Ensino Remoto? Aulas não presenciais? Aulas virtuais? Com quais desses sentidos - ou outros - estamos lidando para exercer nossas práticas em Educação Matemática em tempos da pandemia da COVID-19 quando a "não presença" é necessária? Com que recursos didáticos, metodológicos e tecnológicos a prática docente vem sendo exercida nesses contextos de "não presença"? Em que espaços? Com qual planejamento pedagógico? Qual é a nova centralidade do currículo de matemática? E sobre as avaliações? O que, da prática docente, se viu alterado nesse contexto? A respeito das condições pessoais, familiares, psicológicas e de saúde, como vem se dando o trabalho docente na "não-presença"? E a aprendizagem dos estudantes? Quais são nossas 
expectativas, inquietações e reflexões para os tempos quando a "não presença" cessar e os espaços educacionais tiverem que modificar a sua normalidade em prol da preservação da saúde e da vida? Por onde transita o nosso esperançar?

As publicações da edição temática Experiências e sentidos da "não presença" no ensino e na aprendizagem da matemática em tempos da pandemia da COVID-19 refletem essas preocupações, traduzidas na forma de artigos, ensaios e relatos de experiência produzidos por profissionais da educação de diferentes modalidades e níveis de ensino.

$O$ artigo As licenciaturas em matemática no período pós-pandemia: o que a extensão universitária sugere? discute ações promovidas por licenciandos em matemática, revelando preocupações com a continuidade dos projetos extensionistas durante a pandemia e com a formação inicial de professores que se entrelaça com esses projetos. Além disso, os autores mostram que o projeto desenvolvido na pandemia contribuiu para a compreensão de conceitos de matemática que podem ajudar as pessoas a fazerem uma leitura de mundo crítica a respeito dos dados estatísticos referentes à COVID-19, presentes em gráficos e tabelas veiculados e publicados na imprensa e nas mídias sociais, diariamente, desde que entramos nessa crise sanitária.

Educação de Jovens e adultos, matemática e ensino remoto é um artigo que discute a EJA, suas especificidades e relação com a Educação Matemática, abordando desafios impostos pela pandemia. Os autores apresentam um recorte de uma pesquisa realizada em cinco municípios no Estado de Goiás no ano de 2020. Nesse estudo, acompanharam a trajetória de Cecília, pseudônimo de uma estudante de EJA, na disciplina de Matemática de um curso técnico integrado ao Ensino Médio - Secretariado. Apresentada pelos autores, a história de Cecília - escolar e familiar - revela sentimentos e acontecimentos que representam a história de vida de muitos estudantes de EJA, notadamente de mulheres e mães. Localizada na época de pandemia, esta história mostra como as vidas tiveram suas rotinas em torno da educação muito modificadas para se adaptarem ao ensino remoto. A respeito da Educação Matemática, os autores discutem o fato de que a falta do contato presencial nas aulas remotas altera os modos como alunos e professores se relacionam com os conceitos matemáticos.

O artigo Estágio curricular no ensino remoto: concepções e percepções dos professores em formação inicial discute a proposta e a realização do estágio curricular durante a pandemia, com ensino remoto, em um curso de Licenciatura em Matemática a Distância de uma Universidade Pública Federal do Sul do Rio Grande do Sul. Os autores discutem como a disciplina teve que ajustar sua organização e realização em razão da necessidade de distanciamento. Treze estagiários participaram da pesquisa e responderam, por meio de um questionário on-line, perguntas que revelaram suas concepções e percepções sobre a realização da forma como imposta pela pandemia. Os resultados evidenciaram a visão de cada um dos participantes sobre a oportunidade de realizar o estágio para concluir o curso: enquanto uma parte acreditava ser melhor esperar para realizar estágio presencial, outra parte pensava ser melhor realizá-lo de modo remoto dada à incerteza da volta das aulas presenciais nas escolas, o que poderia atrasar a andamento do curso.

O ensino de matemática na Educação Básica é tema do artigo 'Falo para guardar 8 na cabeça e contar nos dedinhos o restante': estratégias de resolução de problemas adotadas pelas famílias durante a pandemia. $O$ foco de análise são os saberes matemáticos em estratégias de ensino que foram colocadas em prática por mães ao auxiliarem seus filhos nas tarefas escolares, no ciclo de alfabetização (1ำ ao 3ำ ano) de uma escola pública de São Carlos/SP. Foram realizadas entrevistas semiestruturadas virtuais com um grupo de mães que 
se autodeclararam responsáveis pelas tarefas escolares de seus filhos durante o período de ensino remoto na pandemia e, assim, auxiliavam nas tarefas de matemática propostas pelos professores da escola. $\mathrm{Na}$ análise dos dados os autores colocaram em evidências aspectos relacionados a dificuldades encontradas e estratégias adotadas nesse acompanhamento.

A extensão universitária e sua relação com a formação de professores volta ao debate no artigo Formação de professores de matemática em projeto de extensão: percepções docentes em tempos da pandemia da COVID-19. O projeto de extensão é voltado à formação continuada de professores de matemática, do qual participam os estudantes de Licenciatura em Matemática (bolsistas extensionistas), o que promove uma interação entre esses dois tempos da constituição profissional do professor que ensina matemática. Em 2020, as ações do projeto foram realizadas em encontros virtuais, em função da pandemia. Assim, os autores coletaram dados referentes à participação dos envolvidos tanto no modo presencial, anterior à pandemia, quanto no modo remoto. Participaram da pesquisa sete professores da Educação Básica que responderam a um questionário, cujas respostas, depois de analisadas pelos autores, revelaram que apesar das mudanças impostas pela pandemia, os objetivos do projeto foram alcançados.

Google Meet no ensino e na aprendizagem da matemática em tempos da pandemia da COVID-19 em uma turma de licenciatura de matemática é um artigo que apresenta experiências em aulas remotas de uma turma de Licenciatura em Matemática e analisa percepções dos acadêmicos participantes a respeito da utilização de tecnologias digitais no ensino e aprendizagem de matemática, como o aplicativo Google Meet. Os dados foram coletados por meio de observação e de gravação das atividades realizadas pelo Google Meet por oito acadêmicos da disciplina Metodologia e Prática de Ensino de Matemática em uma turma de Licenciatura em Matemática de um Centro de Estudos Superiores do interior do Estado do Amazonas. A análise mostrou que a maior dificuldade encontrada pelos participantes foi o precário acesso à internet.

$O$ artigo Sala de aula invertida adaptada ao ensino remoto: uma proposta de ensino híbrido aplicado à análise combinatória discute práticas pedagógicas realizadas com em uma turma com dezesseis alunos de uma turma de 2 o ano do Ensino Médio de uma instituição privada do interior do Estado do Rio de Janeiro para ensino de conceitos de análise combinatória. O foco está na discussão do modelo de sala de aula invertida como metodologia ativa adaptável ao ensino remoto. Os autores apresentam a sequência didática que foi utilizada na atividade, discutem-na à luz de referências sobre sala de aula invertida e sobre o uso de tecnologias para ensino remoto. O resultado da análise dos dados coletados por meio de observação e de questionários mostrou que a metodologia de ensino Sala de Aula Invertida Adaptada ao Ensino Remoto foi eficaz no aprendizado dos estudantes, mas que é importante a presença de um professor mediador. Além disso, os autores concluíram que adotar o modelo de ensino remoto foi boa alternativa para manutenção das aulas, ainda que aconteçam, em determinadas situações, problemas ligados à conexão com a internet e à configuração dos equipamentos utilizados.

O ensaio A escola fechou. E agora? Discutindo as práticas pedagógicas em Matemática em tempos de COVID-19 discute práticas pedagógicas de professores de matemática de Ensino Médio da rede estadual de educação do Rio de Janeiro a partir de suas percepções sobre as atividades docentes e discentes durante o ensino remoto na pandemia. $\mathrm{Na}$ pesquisa, foram realizadas entrevistas com quatro estudantes de uma escola da rede estadual do Rio de Janeiro e com sua professora de matemática. Os resultados das entrevistas 
mostraram que os estudantes participantes encontraram dificuldades ligadas ao acesso a computador em casa para participarem das aulas on-line e, dessa forma, o smartphone das famílias foi o equipamento mais utilizado para este fim. Além disso, evidenciaram dificuldades relativas ao planejamento e organização para os estudos e atividades das aulas, considerando a necessidade de conciliá-las com a dinâmica familiar. Por parte da professora, o estudo mostrou que também foi necessária adaptação da rotina profissional e pessoal para o modelo de ensino remoto, o que passou pela necessidade de aprender a lidar com recursos tecnológicos para ministrar suas aulas.

No ensaio Algumas reflexões sobre os impactos sofridos pelos sistemas didáticos em tempos de pandemia os autores promovem uma reflexão sobre as mudanças sofridas pelos Sistemas Didáticos (SD) em decorrência da interrupção do ensino presencial nas escolas. Discutem, dessa forma, os novos papéis que foram assumidos pelos estudantes, professores e familiares no desenho de escola colocado em prática durante a pandemia. A discussão teórica se apoia nas ideias de Chevallard sobre Teoria Antropológica do Didático e de Brousseau sobre Sistemas Didáticos.

No ensaio Validações matemáticas na sala de aula: sensações, movimentos e desafios de uma pesquisa que acontece durante a pandemia do novo Coronavírus são discutidos os processos de validação matemática realizados por alunos de nono ano do ensino fundamental que desenvolveram atividades de matemática, de modo remoto, utilizando os recursos tecnológicos que possibilitaram a comunicação e a discussão das resoluções. Além das discussões sobre a importância do trabalho com conjecturas e validações no ensino de matemática, foram revelados resultados sobre a realização das aulas no modo remoto, como por exemplo as dificuldades dos alunos com o acesso à internet e a equipamentos e com a nova rotina de estudos em casa e dos professores em produzir conteúdos nesse contexto e estabelecer uma comunicação adequada com os estudantes.

A disciplina de Tópicos de Educação Matemática I: afetos e desafetos é um relato de experiência que nos apresenta narrativas de professores formadores de professores na condução de uma disciplina de curso de licenciatura em matemática por meio do ensino remoto em uma Instituição de Ensino Superior Pública, que nos levam a reflexões sobre trabalho docente colaborativo. No contexto dado, somos apresentados às formas como esses três docentes lidaram com o trabalho durante a disciplina, que foi planejada e ministrada conjuntamente por eles. As narrativas produzidas são um compartilhamento de vivências que traduzem muito daquilo que outros professores passaram durante a pandemia no exercício de suas práticas pedagógicas. Na análise, os autores dão destaque ao modo colaborativo com que trabalharam no período, que foi potencializado pela necessidade de trabalho remoto.

No relato de experiência Círculos matemáticos: uma experiência com alunos ingressantes no ensino superior no contexto da pandemia Covid-19, a autora apresenta as práticas dos círculos matemáticos em um projeto realizado durante a pandemia com alunos ingressantes do curso de Ciências Econômicas de uma universidade pública do estado de São Paulo. A autora explica o que são os círculos matemáticos e qual sua importância para o ensino e a aprendizagem de matemática e para a integração acadêmica. Na experiência, foram realizados vinte e um encontros semanais fora do horário regular das aulas, no ambiente Google Classroom. No texto, a autora apresenta alguns dos problemas de matemática estudados nos encontros, compartilhando com os leitores essas atividades.

O relato de experiência Decifrando enigma em tempos de pandemia: a resolução de problemas como metodologia na aula de matemática do 60 ano trata da utilização da 
metodologia de resolução de problemas em aulas de matemática na modalidade online, ocorrida na pandemia, para estudantes de cinco turmas de $6^{\circ}$ ano do Ensino Fundamental de uma escola da rede privada de Porto Alegre/RS. A prática se deu na forma de uma caça ao tesouro, adaptada para o modelo de ensino remoto, com uso dos recursos digitais e equipamentos como computadores e smartphones. Segundo análise feita pelas autoras, os estudantes se envolveram de forma positiva nas atividades de resolução de problemas em razão dos desafios em torno das quais elas se deram e, além disso, pela possibilidade do trabalho em grupo, ainda que de modo virtual.

Formação de professores de Matemática na pandemia: reflexões em tempos de crise na educação é um relato de experiência sobre ações pedagógicas de professores formadores de professores, do curso de matemática, para colocar em prática o ensino remoto durante a pandemia. No texto, os autores apresentam as ferramentas tecnológicas utilizadas e os modos como têm lidado com o ensino remoto na pandemia para manutenção das atividades, incluídas ações de integração, como por exemplo o Sarau de Matemática e a continuidade de projetos extensionistas, bem como as práticas de estágio curricular. Segundo os autores, a pandemia provocou no corpo docente a necessidade de revisar suas concepções sobre o ensino para olhar de outras formas para seus fazeres pedagógicos voltados à formação docente.

No relato de experiência GeoGebra grupos e objetos de aprendizagem: um recurso para exploração do raciocínio covariacional em tempos de aulas não presenciais, os autores apresentam uma experiência com o ensino de funções para estudantes do primeiro ano do Ensino Médio de uma escola privada de Santa Catarina, na pandemia, utilizando objetos de aprendizagem do GeoGebra e a plataforma GeoGebra Grupos. As atividades focaram no conceito de função sob a ótica de variação. Os autores concluíram que a utilização do GeoGebra possibilitou a exploração dos conceitos matemáticos utilizando diferentes tipos de representação, o que amplia as possibilidades de compreensão por parte dos estudantes. Além disso, apresentam suas reflexões sobre a transição das aulas presenciais para remotas no período da pandemia, que impuseram ao professor a necessidade de adaptação de práticas pedagógicas e de materiais didáticos.

O ensino e aprendizagem da matemática em contexto pandêmico: com a palavra uma professora dos anos iniciais é um relato de experiência sobre vivências de uma professora que ensina matemática no 20 ano do Ensino Fundamental com o ensino remoto em uma escola pública do interior do Estado da Bahia, durante a pandemia. O texto apresenta narrativas orientadas autobiograficamente, constituídas a partir de dados coletados por meio de um questionário e de entrevistas com a professora participante. Dessa forma, expõe ao leitor o perfil da professora e de seu local de trabalho, as suas impressões com relação ao início do trabalho remoto na pandemia, as ações de planejamento das aulas de matemática no sistema de ensino remoto, os seus olhares sobre as aulas de matemática ministradas durante a pandemia.

O relato de experiência Prova escrita em aulas remotas: uma experiência no oitavo ano apresenta discussão sobre a aplicação de uma prova escrita de matemática para uma turma de 8 o ano do Ensino Fundamental de uma escola privada de um Município do interior do Estado do Paraná, durante aulas remotas, na perspectiva da avaliação como um momento de aprendizagem. Na pandemia, uma das discussões mais desafiadoras refere-se à avaliação dos alunos durante o ensino remoto. As autoras discutem esse tema e suas particularidades voltadas à aprendizagem de matemática. No texto, as autoras concluem que a avaliação por 
meio de diferentes estratégias tanto ajuda o professor quanto os alunos, pois assim o momento de avaliação pode se constituir também em uma situação de aprendizagem.

No texto 'Sem mais nem menos on-line': formação continuada de professores de matemática durante a pandemia, os autores relatam a experiência com ações desenvolvidas, na pandemia, em um projeto de extensão universitária voltado à formação continuada de professores de matemática da Educação Básica. No relato de experiência, os autores descrevem a participação de professores e avaliam as potencialidades de um projeto colaborativo e on-line para a formação continuada de professores de matemática. No período de pandemia, as atividades do projeto foram realizadas por meio de lives pelo Instagram voltadas a estudantes do Ensino Fundamental II e Ensino Médio e webconferências para professores de matemática. Os dados foram coletados junto aos professores participantes, em questionários do Google Forms. Analisados, mostraram o perfil do público participante, suas motivações, as ações que eles desenvolveram a partir da participação no projeto e suas percepções a respeito das atividades das quais participaram. Segundo os autores, participantes relataram que o projeto permitiu que eles mudassem a forma de pensar o ensino de matemática.

Os textos desta edição ficarão como registro histórico de experiências em torno da Educação Matemática durante a pandemia de COVID-19. Mostrarão como, por exemplo, para se adaptarem às exigências mediante as restrições, professores, estudantes e famílias estão lidando com os modelos de aula e a necessidade de manterem os vínculos humanos em torno da educação ainda que afastados uns dos outros; pesquisadores replanejaram suas investigações neste período para continuarem em ação mesmo que sem interação presencial; projetos de extensão universitária continuaram seguindo seus objetivos em relação à comunidade; se deram diferentes experiências e formas de analisá-las. Conhecer essa realidade, pensar sobre ela, nos ajudará a compreender os problemas atuais e planejar como enfrentá-los no futuro, pois mudanças serão necessárias não somente para resolver a crise que vivemos, mas também para repensar a Educação Matemática.

Figura 6-Obra de @raangul

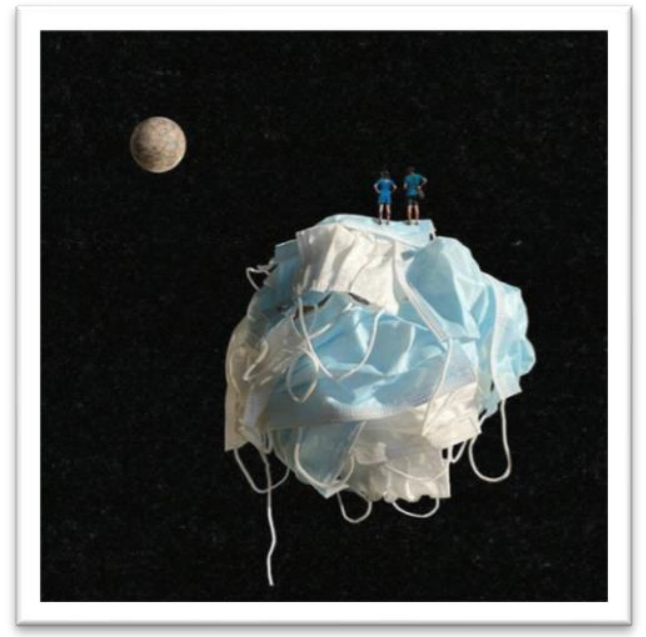

Fonte: CAM The Covid Art Museum - https://www.instagram.com/p/CLFLZe1DMAW

Assim, seguimos trabalhando, vivendo experiências e esperando uma Educação Matemática fortalecida para superação da crise. Experiências como em Larrosa. Espera do esperançar de Paulo Freire (FREIRE, 1997) que nos move a seguir, agir e ir adiante. 


\section{Referências}

CAM - The Covid Art Museum. Disponível em: https://www.instagram.com/covidartmuseum.

FREIRE, Paulo. Educação como prática da liberdade. Rio de Janeiro: Paz e Terra, 1967.

FREIRE, Paulo. Pedagogia do oprimido. 17. ed. Rio de Janeiro: Paz e Terra, 1987.

FREIRE, Paulo. Pedagogia da autonomia: saberes necessários à prática educativa. 25. ed. São Paulo: Paz e Terra, 1996.

FREIRE, Paulo. Pedagogia da esperança: um reencontro com a pedagogia do oprimido.

Rio de Janeiro: Paz e Terra, 1997.

FREIRE, Paulo. Carta de Paulo Freire aos professores. Estudos Avançados, [S. I.], v. 15, n. 42, p. 259268, 2001.

LARROSA, Jorge. Notas sobre a experiência e o saber de experiência. Revista Brasileira de Educação, Rio de Janeiro, n. 19, p. 20-28, jan./fev./mar./abr., 2002.

LARROSA, Jorge. Experiência e alteridade em Educação. Revista Reflexão e Ação, Santa Cruz do Sul, v.19, n. 2, p. 04-27, jul./dez., 2011.

WHO - WORLD HEALTH ORGANIZATION. COVID-19 Strategy Update, 2020. Disponível em: http://tiny.cc/iotkuz. Acesso em: 26 out. 2021.

WHO - WORLD HEALTH ORGANIZATION. WHO Coronavirus (COVID-19) Dashboard, 2021. Disponível em: https://covid19.who.int/table . Acesso em: 26 out. 2021. 